\title{
Polymorphism in one-carbon metabolism pathway affects survival of gastric cancer patients: Large and comprehensive study
}

\author{
Tingting Zhao ${ }^{1,5, *}$, Dongying Gu ${ }^{1, *}$, Zhi Xu ${ }^{1, *}$, Xinying Huo ${ }^{1}$, Lili Shen ${ }^{1}$, Chun Wang ${ }^{1}$, \\ Yongfei Tang ${ }^{2}$, Peng W ${ }^{1}$, Jason $\mathrm{He}^{3}$, Weida Gong ${ }^{4}$, Ming-Liang He ${ }^{6}$, Jinfei Chen ${ }^{1,7}$ \\ ${ }^{1}$ Department of Oncology, Nanjing First Hospital, Nanjing Medical University, Nanjing, China \\ ${ }^{2}$ Department of Surgery, Yixing People's Hospital, Yixing, China \\ ${ }^{3}$ College of Letter and Sciences, University of California at Berkeley, CA, USA \\ ${ }^{4}$ Department of Surgery, Yixing Cancer Hospital, Yixing, China \\ ${ }^{5}$ Stanley Ho Center for Emerging Infectious Diseases, and Li Ka Shing Institute of Health Sciences, Faculty of Medicine, The \\ Chinese University of Hong Kong, Hong Kong, China \\ ${ }^{6}$ Department of Biomedical Sciences, City University of Hong Kong, Hong Kong, China \\ ${ }^{7}$ Collaborative Innovation Center for Cancer Personalized Medicine, Nanjing Medical University, Nanjing, China \\ *These authors have contributed equally to this work
}

Correspondence to:

Jinfei Chen, e-mail: jinfeichen@sohu.com

Ming-Liang He, e-mail: mlhe7788@gmail.com

Keywords: one-carbon metabolism (OCM), single nucleotide polymorphism (SNP), gastric cancer

Received: December 21,2014 Accepted: January 31, $2015 \quad$ Published: March 25, 2015

\section{ABSTRACT}

Although it has been shown that polymorphisms in one-carbon metabolism (OCM) pathway are associated with gastric cancer (GC), their interactions and contributions for patients' survival are elusive. In this study, we investigated the effects of polymorphisms and their interactions on the survival of GC patients, including genes of Methylenetetrahydrofolate reductase (MTHFR 677C > T, 1298A > C), Methionine synthase reductase (MTRR 66A > G), Methionine synthase (MTR 2756A > G), and Thymidylate synthase (TS 3'-UTR ins6 > del6, 5'-UTR 2R > 3R). We recruited 919 GC patients from 1998 to 2006. The Kaplan-Meier plots, Cox regression analyses and the log-rank tests were carried out in this study. MTHFR 1298CC genotype showed protective effect $(H R=0.444,95 \% \mathrm{CI}=0.210-0.940)$. MTRR $66 \mathrm{GA}+\mathrm{GG}$ genotypes decreased the risk of death $(\mathrm{HR}=0.793,95 \% \mathrm{CI}=0.651-0.967)$ in general, and in subgroups with more pronounced diffuse type, greater depth of invasion (T2/T3/T4), higher level lymph node metastasis (N1/N2/N3), advanced TNM stages (II/III level) and 5-Fu treatment. However, the improved survival disappeared when GC patients simultaneously had MTR 2756 GA + GG genotypes ( HR $=1.063,95 \%$ CI $=0.750-1.507)$. Although MTRR 66GA genotype was not associated with the survival of GC patients, patients with simultaneous MTRR 66GA and MTR 2756AA genotypes exhibited significant risk reduction of death $(\mathrm{HR}=0.773,95 \% \mathrm{CI}=0.609-0.981)$. MTHFR $1298 \mathrm{CA}+\mathrm{CC}$ combined with TS 5-UTR $2 R 3 R+3 R 3 R$ genotypes ( $\mathrm{HR}=0.536,95 \% \mathrm{CI}=0.315-0.913$ ) also increased patient survival rates. Our results suggest that the MTRR 66A $>G$ and MTHFR 1298A > C polymorphisms may be useful prognostic biomarkers for GC patients.

\section{INTRODUCTION}

Gastric cancer (GC), the fourth most common and the second most deadly cancer worldwide, is particularly prevalent in developing countries [1]. Although significant progress has been achieved in multimodal therapy strategies, such as combination therapy with surgery, chemotherapy, radiotherapy, or targeted therapy, the prognosis still remains 
poor with 5-year overall survival rates less than $25 \%$ [2]. Biomarkers for early diagnosis are important in deciding therapeutic options, as well as improving treatment efficiency and prognosis prediction [3].

Genetic factors play crucial roles in initiation of carcinogenesis and cancer development. Although gastric carcinogenesis undergoes highly complicated processes (e.g., abrogated gene expression, abnormal cell proliferation, resistance to apoptosis, dedifferentiation, enhanced survival, escape of immune surveillance, and metastasis) [4, 5], abrogation of gene expression or function caused by genetic changes (i.e., deletion, amplification and mutation) is the main force driving normal gastric cells into cancer cells. It has been shown that dysfunctions of one-carbon metabolism associated genes contribute to carcinogenesis via affecting DNA methylation, synthesis and repair [6]. One-carbon metabolism (OCM) pathway is a centered pathway involved in folate metabolism and DNA synthesis. It contains several crucial enzymatic reactions from folate uptake to synthesis of S-adenosylmethionine (SAM) [7]. Methylenetetrahydrofolate reductase (MTHFR) is a vitamin B2-dependent enzyme that carries out an irreversible conversion of 5,10-methylene-tetrahydrofolate (5,10-MTHF) to 5-methyl-tetrahydrofolate (5-MTHF) [8]. This is the rate-limiting step for OCM because 5,10MTHF is the substrate for three other enzymatic reactions. Methionine synthase (MTR) catalyzes the remethylation of homocysteine to methionine [9], the residue critical for maintaining adequate intercellular folate level. Methionine synthase reductase (MTRR) maintains MTR in its active form. Thymidylate synthase (TS) catalyzes the reductive methylation of dUMP by 5,10-MTHF to form dTMP and dihydrofolate, a rate-limiting step in DNA synthesis [10]. TS is an essential enzyme in proliferating cells and is also an important target for a variety of chemotherapeutic drugs, e.g. 5-FU.

Previous studies have identified that functional polymorphisms of these genes in the OCM pathway were associated with human cancers, including colorectal cancer, head and neck cancer, esophagus cancer, hepatocellular cancer, lung cancer, renal cell carcinoma and gastric cancer [11-18]. Common variants of MTHFR (rs1801133, 677 $C>T$, Ala222Val; and rs1801131, $1298 A>C$, Glu429Ala) reduced enzyme activity and plasma folate levels, resulting in hypomethylation [19]. Suboptimal methyl supply led to dysfunction of DNA methylation, a process highly associated with GC etiology [20]. The polymorphisms of MTR (rs1805087, $2756 A>G$, Asp868Gly) and MTRR (rs1801394, 66A $>G$, ILe22Met), which were associated with hyperhomocysteinemia [21], impaired remethylation of homocysteine to methionine. The copy number of 28-bp tandem repeats in the $5^{\prime}$-untranslated region (5'-UTR) of TS gene affected the translational efficiency [22]. In a reporter assay, the 5'-UTR of TS with 3-repeats (3R) displayed much higher luciferase activities than that with 2-repeats (2R), suggesting this tandem repeats may enhance the assembly of translational machinery or mediate more effective binding between ribosome and TS mRNA [23]. It was shown that intratumoral TS protein level was associated with the sensitivity of chemotherapy (e.g. 5-FU) [24, 25]. A novel polymorphism with 6-bp deletion of the sequence TTAAAG at nt1494 was found to be associated with decreased TS mRNA stability in the 3-untranslated region (3'-UTR) of $T S$ gene. Therefore, the deletion suppressed its expression $[26,27]$. However, whether the 5'-UTR and $3^{\prime}$-UTR polymorphisms interact each other and display synergistic or counteractive effects on GC have not been investigated.

The effects of polymorphisms of individual gene or combinations of two genes have been investigated on GC survival. Whether these polymorphisms would interact with each other and display certain synergistic effects have not been reported. In this study, for the first time, based on large-number clinical data analysis, we systematically investigated the comprehensive effects of polymorphisms of four genes involved in OCM pathway on the clinical outcomes of GC patients.

\section{RESULTS}

\section{Clinical features of the study subjects}

The clinical characteristics of 919 retained GC patients were described in Table 1 . The median age of the study subjects was 62.0 years (range, $28-83$ years). All of the GC patients underwent the surgical resections and 297 patients received chemotherapy. 426 patients died during the 119.0 months of follow-up. The survival time was significantly related to varieties in tumor size, histological type and depth of invasion, lymph node metastasis and TNM stage (all log-rank $p<0.05$ ). In particular, patients with tumor size $>5 \mathrm{~cm}$ (MST, 50 months) had a 41\% significantly higher risk of death $(\mathrm{HR}=1.41,95 \% \mathrm{CI}=$ $1.16-1.71, p<0.001$ ) when compared with those with tumor size $\leq 5 \mathrm{~cm}$ (MST, 98 months). The intestinal-type patients (MST, 77 months) had a 64\% significantly lower risk of death $(\mathrm{HR}=1.36,95 \% \mathrm{CI}=1.13-1.54, p<0.001)$ than diffuse-type patients (MST, 62 months). Patients with lymph node metastasis (MST, 46 months) also had a 76\% higher risk of death $(\mathrm{HR}=1.76,95 \% \mathrm{CI}=1.43-2.16$, $p<0.001$ ) when compared to those with no lymph node metastasis (MST, 80 months). Furthermore, as the depth of invasion and TNM stage increased, the risk of death also exhibited an obvious increase (log-rank $p<0.001)$.

\section{Prolongation of patient survival with $M T R R$ $66 A>G$ polymorphism}

The relationships between individual polymorphisms and survival of GC patients in different genetic models were assessed by Cox regression analyses. Codominant, dominant and recessive models were 
Table 1: Gastric cancer patients' characteristics and clinical features

\begin{tabular}{|c|c|c|c|c|c|}
\hline Variable & Patients $(n=919)$ & Deaths $(n=426)$ & MST (months) & Log-rank $p$ & $\operatorname{HR}(96 \% \mathrm{CI})^{\mathrm{a}}$ \\
\hline \multicolumn{6}{|l|}{ Age (years) } \\
\hline$\leq 60$ & 432 & 198 & 89 & 0.372 & 1.00 \\
\hline$>60$ & 487 & 228 & 62 & & $1.090(0.90-1.32)$ \\
\hline \multicolumn{6}{|l|}{ Sex } \\
\hline Male & 706 & 323 & 74 & 0.384 & 1.00 \\
\hline Female & 213 & 103 & 63 & & $1.10(0.88-1.38)$ \\
\hline \multicolumn{6}{|l|}{ Tumor size } \\
\hline$<5 \mathrm{~cm}$ & 570 & 241 & 98 & $<0.001$ & 1.00 \\
\hline$>5 \mathrm{~cm}$ & 349 & 185 & 50 & & $1.41(1.16-1.71)$ \\
\hline \multicolumn{6}{|l|}{ Tumour site } \\
\hline Non-cardia & 313 & 141 & 77 & 0.354 & 1.00 \\
\hline Cardia & 606 & 285 & 67 & & $0.91(0.74-1.11)$ \\
\hline \multicolumn{6}{|c|}{ Histological type } \\
\hline Intestinal & 393 & 152 & $77^{\mathrm{b}}$ & $<0.001$ & 1.00 \\
\hline Diffuse & 526 & 274 & 62 & & $1.36(1.13-1.54)$ \\
\hline \multicolumn{6}{|c|}{ Depth of invasion } \\
\hline $\mathrm{T} 1$ & 177 & 56 & $86^{\mathrm{b}}$ & $<0.001$ & 1.00 \\
\hline $\mathrm{T} 2$ & 134 & 59 & 78 & & $1.52(1.09-2.19)$ \\
\hline $\mathrm{T} 3$ & 6 & 3 & 70 & & $1.46(1.23-2.37)$ \\
\hline $\mathrm{T} 4$ & 583 & 295 & 52 & & $1.91(1.43-2.54)$ \\
\hline \multicolumn{6}{|c|}{ Lymph node metastasis } \\
\hline N0 & 362 & 129 & 80 & $<0.001$ & 1.00 \\
\hline $\mathrm{N} 1 / \mathrm{N} 2 / \mathrm{N} 3$ & 546 & 290 & 46 & & $1.76(1.43-2.16)$ \\
\hline \multicolumn{6}{|c|}{ Distant metastasis } \\
\hline M0 & 903 & 417 & 70 & 0.437 & 1.00 \\
\hline M1 & 15 & 8 & 47 & & $1.32(0.66-2.65)$ \\
\hline \multicolumn{6}{|l|}{ TNM stage } \\
\hline I & 239 & 80 & $84^{\mathrm{b}}$ & & 1.00 \\
\hline II & 198 & 80 & 70 & $<0.001$ & $1.29(0.92-1.77)$ \\
\hline III & 452 & 248 & 41 & & $2.03(1.57-2.61)$ \\
\hline IV & 22 & 12 & 40 & & $2.13(1.16-3.91)$ \\
\hline \multicolumn{6}{|c|}{ Chemotherapy } \\
\hline No & 613 & 285 & 74 & 0.450 & 1.00 \\
\hline Yes & 297 & 135 & 60 & & $1.08(0.88-1.33)$ \\
\hline
\end{tabular}

${ }^{\mathrm{a}}$ Adjusted for age and sex.

${ }^{b}$ Mean survival time was provided when MST could not be calculated.

'Information was not available for two patients. 
applied in this study (Table 2). We first observed that MTRR $66 G G$ genotype significantly protected GC patients from death. The MST of patients with GG genotype was extended from 51 to 87 months $(\mathrm{HR}=0.500,95 \% \mathrm{CI}=$ $0.291-0.856, p=0.014)$ when compared to those with $A A$ genotype. A similar result was also obtained in a recessive model $(\mathrm{HR}=0.537,95 \% \mathrm{CI}=0.315-0.915, p=0.019)$. Further analysis of MTRR $66 \mathrm{~A}>\mathrm{G}$ polymorphism in the dominant model revealed a remarkably longer survival time in GC patients (MST, 97.0 months; HR $=0.793,95 \%$ $\mathrm{CI}=0.651-0.967, p=0.022)$ as compared to that in $A A$ homozygote (Table 2). The overall survival of GC patients with $66 A>G$ dominant genotypes $(A G+G G)$ was presented in Figure 1. Heterozygote $66 A>G$ genotypes exhibited marginal prolongation of survival of GC patients $(\mathrm{HR}=0.883,95 \% \mathrm{CI}=0.684-1.028$, Table 2$)$.

\section{MTHFR 1298CC genotype associate with decreased risk of death}

In the case of MTHFR $1298 A>C$ polymorphism, patients with homozygote $C C$ genotype (MST, 81 months) had a $44 \%$ significantly lower risk of death $(\mathrm{HR}=0.440$, $95 \% \mathrm{CI}=0.210-0.940)$ when compared with those with $A A$ genotype (MST, 65 months). A similar result was also obtained in a recessive model $(\mathrm{HR}=0.446,95 \% \mathrm{CI}=$ 0.211-0.942, Table 2).

In the case of MTHFR $677 C>T$ and other polymorphisms $\left(M T R 2756 A>G, T S 5^{\prime}\right.$-UTR $2 R>3 R$ and 3'-UTR 6bp ins $>$ del), no significant associations were identified between survival time and polymorphisms in any genetic models (Table 2).

\section{MTRR 66A $>G$ polymorphism on protection of GC patients}

To better demonstrate the protective effect of $66 \mathrm{~A}>G$ polymorphism on GC survival in detail, we performed stratified analyses based on tumour size, tumour site, histological type, depth of invasion, lymph node metastasis, distant metastasis, TNM stage and chemotherapy. No obvious association was detected with tumor size or location in GC patients (Table 3). Surprisingly, we detected significant protection of $G A+G G$ genotypes in patients

\section{Table 2: Genotypes of MTRR, MTHFR, MTR and TS polymorphisms and gastric cancer patients'}

survival

\begin{tabular}{|c|c|c|c|c|c|c|}
\hline Genetic model & Genotypes & patients & Deaths & MST (months) & $\log -\operatorname{rank} P$ & $\operatorname{HR}(95 \% C I)^{\mathrm{a}}$ \\
\hline \multicolumn{7}{|c|}{ MTRR rs1801394 A66G } \\
\hline \multirow[t]{3}{*}{ Codominant model } & AA & 489 & 242 & 51 & 0.014 & 1.00 \\
\hline & GA & 347 & 151 & 80 & & $0.838(0.684-1.028)$ \\
\hline & GG & 49 & 14 & $87^{b}$ & & $0.500(0.291-0.856)$ \\
\hline \multirow[t]{2}{*}{ Dominant model } & AA & 489 & 242 & 51 & 0.022 & 1.00 \\
\hline & GA/GG & 396 & 165 & 97 & & $0.793(0.651-0.967)$ \\
\hline \multirow[t]{2}{*}{ Recessive model } & AA/GA & 836 & 393 & 65 & 0.019 & 1.00 \\
\hline & GG & 49 & 14 & $87^{b}$ & & $0.537(0.315-0.915)$ \\
\hline \multicolumn{7}{|c|}{ MTHFR rs1801131 A1298C } \\
\hline \multirow[t]{3}{*}{ Codominant model } & AA & 640 & 301 & 65 & 0.090 & 1.00 \\
\hline & $\mathrm{CA}$ & 236 & 110 & 63 & & $0.985(0.792-1.225)$ \\
\hline & $\mathrm{CC}$ & 28 & 7 & $81^{\mathrm{b}}$ & & $0.444(0.210-0.940)$ \\
\hline \multirow[t]{2}{*}{ Dominant model } & AA & 640 & 301 & 65 & 0.429 & 1.00 \\
\hline & $\mathrm{CA} / \mathrm{CC}$ & 264 & 117 & 89 & & $0.918(0.742-1.137)$ \\
\hline \multirow[t]{2}{*}{ Recessive model } & $\mathrm{AA} / \mathrm{CA}$ & 876 & 411 & 65 & 0.042 & 1.00 \\
\hline & $\mathrm{CC}$ & 28 & 7 & $81^{\mathrm{b}}$ & & $0.446(0.211-0.942)$ \\
\hline \multicolumn{7}{|c|}{ MTHFR rs1801133 C677T } \\
\hline \multirow[t]{3}{*}{ Codominant model } & $\mathrm{CC}$ & 313 & 151 & 60 & 0.793 & 1.00 \\
\hline & $\mathrm{TC}$ & 438 & 200 & 78 & & $0.940(0.761-1.161)$ \\
\hline & TT & 141 & 63 & 63 & & $0.918(0.684-1.231)$ \\
\hline
\end{tabular}

(Continued) 


\begin{tabular}{|c|c|c|c|c|c|c|}
\hline Genetic model & Genotypes & patients & Deaths & MST (months) & $\log -\operatorname{rank} P$ & $\operatorname{HR}(95 \% C I)^{a}$ \\
\hline \multirow[t]{2}{*}{ Dominant model } & $\mathrm{CC}$ & 313 & 151 & 60 & 0.51 & 1.00 \\
\hline & $\mathrm{TC} / \mathrm{TT}$ & 579 & 263 & 74 & & $0.935(0.766-1.143)$ \\
\hline \multirow[t]{2}{*}{ Recessive model } & $\mathrm{CC} / \mathrm{TC}$ & 751 & 351 & 65 & 0.708 & 1.00 \\
\hline & $\mathrm{TT}$ & 141 & 63 & 63 & & $0.951(0.727-1.244)$ \\
\hline \multicolumn{7}{|c|}{ MTR rs1805087 A2756G } \\
\hline \multirow[t]{3}{*}{ Codominant model } & AA & 684 & 314 & 52 & 0.041 & 1.00 \\
\hline & GA & 149 & 69 & 88 & & $1.033(0.796-1.341)$ \\
\hline & GG & 7 & 0 & $75^{\mathrm{b}}$ & & 0 \\
\hline \multirow[t]{2}{*}{ Dominant model } & AA & 688 & 317 & 67 & 0.038 & 1.00 \\
\hline & GA/GG & 149 & 69 & 70 & & $0.972(0.749-1.261)$ \\
\hline \multirow[t]{2}{*}{ Recessive model } & AA/GA & 830 & 386 & 65 & 0.053 & 1.00 \\
\hline & GG & 7 & 0 & $75^{\mathrm{b}}$ & & $0.049(0.001-3.620)$ \\
\hline \multicolumn{7}{|c|}{ TYMS 5-UTR 2R > 3R } \\
\hline \multirow[t]{3}{*}{ Codominant model } & 2R2R & 43 & 24 & 35 & 0.279 & 1.00 \\
\hline & 2R3R & 276 & 113 & 70 & & $0.807(0.522-1.248)$ \\
\hline & 3R3R & 51 & 27 & 78 & & $0.732(0.481-1.115)$ \\
\hline \multirow[t]{2}{*}{ Dominant model } & $2 \mathrm{R} / 2 \mathrm{R}$ & 43 & 24 & 35 & 0.184 & 1.00 \\
\hline & 2R3R/3R3R & 794 & 357 & 74 & & $0.758(0.501-1.146)$ \\
\hline \multirow[t]{2}{*}{ Recessive model } & $2 \mathrm{R} 2 \mathrm{R} / 2 \mathrm{R} 3 \mathrm{R}$ & 319 & 154 & 62 & 0.216 & 1.00 \\
\hline & 3R3R & 518 & 227 & 78 & & $0.880(0.717-1.080)$ \\
\hline \multicolumn{7}{|c|}{ TYMS 3-UTR 6bp ins/del } \\
\hline \multirow[t]{3}{*}{ Codominant model } & $\mathrm{I} / \mathrm{I}$ & 61 & 30 & 46 & 0.682 & 1.00 \\
\hline & $\mathrm{D} / \mathrm{I}$ & 410 & 193 & 63 & & $0.948(0.645-1.393)$ \\
\hline & $\mathrm{D} / \mathrm{D}$ & 413 & 187 & 77 & & $0.880(0.598-1.294)$ \\
\hline \multirow[t]{2}{*}{ Dominant model } & $\mathrm{I} / \mathrm{I}$ & 61 & 30 & 46 & 0.63 & 1.00 \\
\hline & $\mathrm{DI} / \mathrm{DD}$ & 823 & 380 & 70 & & $0.913(0.630-1.324)$ \\
\hline \multirow[t]{2}{*}{ Recessive model } & II/DI & 471 & 223 & 63 & 0.407 & 1.00 \\
\hline & $\mathrm{D} / \mathrm{D}$ & 413 & 187 & 77 & & $0.922(0.759-1.119)$ \\
\hline
\end{tabular}

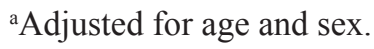

${ }^{b}$ Mean survival time was provided when MST could not be calculated.

with more aggressively diffused tumors than in patients with $A A$ genotype (MST 70 months vs. 37 months, $\mathrm{HR}=$ $0.744,95 \% \mathrm{CI}=0.58-0.954, p=0.02$ ). Similar results were obtained in subgroups with advanced tumors. Although there was no detectable protection in T1, N0, M0, TNM stage I/II subgroups, $G A+G G$ genotypes significantly prolonged the life of GC patients in subgroups of T2/T2/ T3 level depth of invasion $(\mathrm{HR}=0.724,95 \% \mathrm{CI}=0.580$ $0.900, p=0.004), \mathrm{N} 1 / \mathrm{N} 2 / \mathrm{N} 3$ level lymph node metastasis $(\mathrm{HR}=0.772,95 \% \mathrm{CI}=0.607-0.981, p=0.035)$, no distance metastasis $(\mathrm{HR}=0.785,95 \% \mathrm{CI}=0.643-0.958$, $p=0.017)$ and II/III level TNM stages (HR $=0.771,95 \%$ CI $=0.599-0.994, p=0.045$ ). We also noticed that after treating with 5-Fluorouracil, patients with $G A+G G$ genotypes showed longer survival time than those with $A A$ genotype $(\mathrm{HR}=0.668,95 \% \mathrm{CI}=0.470-0.949, p=0.024)$.

\section{Effects of polymorphism interactions on patient survival}

Considering the intricate interactions among the genes described above, we tested polymorphism interactions on 
Table 3: Stratification analysis of the MTRR $66 A>G$ polymorphism and gastric cancer patient's survival

\begin{tabular}{|c|c|c|c|c|c|}
\hline \multirow[t]{2}{*}{ Variables } & \multicolumn{2}{|c|}{ Genotypes (Dominant model) } & \multirow{2}{*}{$\begin{array}{r}\text { MST(AA/ } \\
\text { GA+GG) }\end{array}$} & \multirow[t]{2}{*}{$\operatorname{HR}(95 \% \mathrm{CI})^{\mathrm{a}}$} & \multirow[t]{2}{*}{$P_{\text {Heterogeneity }}$} \\
\hline & AA & GA/GG & & & \\
\hline $\operatorname{Total}(N=885)$ & $489 / 242$ & $396 / 165$ & $51 / 97$ & $0.793(0.651-0.967)$ & 0.022 \\
\hline \multicolumn{6}{|l|}{ Tumor size } \\
\hline$\leq 5 \mathrm{~cm}$ & $303 / 139$ & $249 / 93$ & $70 / 79^{\mathrm{b}}$ & $0.773(0.595-1.006)$ & 0.055 \\
\hline$>5 \mathrm{~cm}$ & $186 / 103$ & $147 / 72$ & $43 / 63$ & $0.798(0.589-1.081)$ & 0.145 \\
\hline \multicolumn{6}{|l|}{ Tumor site } \\
\hline Non-cardia & $327 / 165$ & $257 / 109$ & $50 / 73^{\mathrm{b}}$ & $0.813(0.639-1.036)$ & 0.094 \\
\hline Cardia & $162 / 77$ & $139 / 56$ & $52 / 97$ & $0.751(0.532-1.061)$ & 0.105 \\
\hline \multicolumn{6}{|c|}{ Histological type } \\
\hline Intestinal type & $205 / 80$ & $174 / 64$ & $75^{b} / 80^{b}$ & $0.903(0.650-1.254)$ & 0.542 \\
\hline Diffuse type & $284 / 162$ & $222 / 101$ & $37 / 70$ & $0.744(0.580-0.954)$ & 0.02 \\
\hline \multicolumn{6}{|c|}{ Depth of invasion } \\
\hline $\mathrm{T} 1$ & $92 / 28$ & $81 / 27$ & $85^{\mathrm{b}} / 84^{\mathrm{b}}$ & $1.114(0.657-1.891)$ & 0.688 \\
\hline $\mathrm{T} 2 / \mathrm{T} 3 / \mathrm{T} 4$ & $386 / 208$ & $310 / 134$ & $43 / 78$ & $0.724(0.582-0.900)$ & 0.004 \\
\hline \multicolumn{6}{|c|}{ Lymph node metastasis } \\
\hline N0 & $190 / 73$ & $159 / 50$ & $77^{\mathrm{b}} / 85^{\mathrm{b}}$ & $0.788(0.550-1.130)$ & 0.195 \\
\hline $\mathrm{N} 1 / \mathrm{N} 2 / \mathrm{N} 3$ & $291 / 165$ & $234 / 112$ & $37 / 65$ & $0.772(0.607-0.981)$ & 0.035 \\
\hline \multicolumn{6}{|c|}{ Distant metastasis } \\
\hline M0 & $481 / 238$ & $390 / 162$ & $51 / 97$ & $0.785(0.643-0.958)$ & 0.017 \\
\hline M1 & $8 / 4$ & $5 / 2$ & $40 / 27^{b}$ & $1.028(0.183-5.759)$ & 0.975 \\
\hline \multicolumn{6}{|l|}{ TNM stage } \\
\hline $\mathrm{I} / \mathrm{II}$ & $234 / 93$ & $187 / 59$ & $76 \mathrm{~b} / 85^{\mathrm{b}}$ & $0.793(0.551-1.058)$ & 0.105 \\
\hline III/IV & 252147 & $205 / 103$ & $36 / 62$ & $0.771(0.599-0.994)$ & 0.045 \\
\hline \multicolumn{6}{|l|}{ Chemotherapy } \\
\hline NO 5-FU & $349 / 170$ & $252 / 110$ & $65 / 64$ & $0.870(0.684-1.106)$ & 0.254 \\
\hline 5-FU & $140 / 72$ & $144 / 55$ & $51 / 78^{b}$ & $0.668(0.470-0.949)$ & 0.024 \\
\hline
\end{tabular}

${ }^{\text {a} A d j u s t e d ~ f o r ~ a g e ~ a n d ~ s e x . ~}$

${ }^{b}$ Heterogeneity test for differences between groups.

'Information was not available for two patients.

the survival of GC patients (Supplementary Table S1-S3). In univariate analysis, MTRR $66 G A+G G$ genotypes significantly decreased risk of death, but the improved survival disappeared when GC patients simultaneously had MTR $2756 G A+G G$ genotypes $(\mathrm{HR}=1.063,95 \% \mathrm{CI}=$ $0.750-1.507$, log-rank $p=0.730$, Table 4). Interestingly, the protective effect of MTRR $66 G A+G G$ genotypes was maintained in patients with MTR 2756AA genotypes (HR $=0.720,95 \% \mathrm{CI}=0.569-0.910, \log$-rank $p=0.006$ ). The MTRR 66GA genotype was not associated with the survival of GC patients in univariate analysis, but patients with simultaneous MTRR 66GA and MTR 2756AA genotypes exhibited significant risk reduction of death $(\mathrm{HR}=0.773$, $95 \%$ CI $=0.609-0.981, \log$-rank $p=0.034$ ). However, no significant protective effects were found in patients with MTRR 66GA and MTR 2756GA genotypes (HR $=1.112$, $95 \% \mathrm{CI}=0.764-1.617, \log$-rank $p=0.580$ ). The effects of MTRR $66 \mathrm{~A}>G$ interaction with MTR 2756A $>G$ on the survival of GC patients in dominant model and heterozygote model were shown in Figure 2A and Figure 2B. 
Table 4: The effects of gene-gene interactions on the survival of gastric cancer patients

\begin{tabular}{|c|c|c|c|c|c|}
\hline combined genotypes & patients & Deaths & $\begin{array}{c}\text { MST } \\
\text { (months) }\end{array}$ & $\boldsymbol{P}$ & HR $(95 \% C I)^{a}$ \\
\hline \multicolumn{6}{|l|}{ MTHFR $1298 A>C$ and TS5-UTR $2 R>3 R$} \\
\hline MTHFR 1298AA+TS5-UTR 2R2R & 26 & 16 & 30 & 0.111 & 1.00 \\
\hline MTHFR $1298 A A+T S 5-\mathrm{UTR} 2 R 2 R+2 R 3 R$ & 565 & 262 & 67 & 0.790 & $0.636(0.3840-1.054)$ \\
\hline MTHFR 1298CC+CA+TS5-UTR 2R2R & 14 & 8 & 33 & 0.510 & $0.752(0.322-1.757)$ \\
\hline MTHFR $1298 C C+C A+T S 5-\mathrm{UTR} 2 R 2 R+2 R 3 R$ & 225 & 91 & 98 & 0.022 & $0.536(0.315-0.913)$ \\
\hline \multicolumn{6}{|l|}{$M T R R 66 A>G$ and $M T R 2756 A>G$} \\
\hline MTRR $66 A A+M T R 2756 A A$ & 373 & 187 & 50 & 0.016 & 1.00 \\
\hline$M T R R 66 A A+M T R 2756 G G+G A$ & 75 & 30 & $69^{b}$ & 0.082 & $0.710(0.483-1.044)$ \\
\hline$M T R R 66 G G+G A+M T R 2756 A A$ & 286 & 112 & 75 & 0.006 & $0.720(0.569-0.910)$ \\
\hline$M T R R 66 G G+G A+M T R 2756 G G+G A$ & 70 & 38 & 52 & 0.730 & $1.063(0.750-1.507)$ \\
\hline \multicolumn{6}{|l|}{$M T R R 66 A>G$ and $M T R 2756 A>G$} \\
\hline MTRR $66 A A+M T R 2756 A A$ & 373 & 187 & 50 & 0.094 & 1.00 \\
\hline MTRR $66 A A+M T R 2756 G A$ & 69 & 30 & $65^{\mathrm{b}}$ & 0.223 & $0.787(0.535-1.157)$ \\
\hline MTRR $66 G A+M T R 2756 A A$ & 255 & 106 & 98 & 0.034 & $0.773(0.609-0.981)$ \\
\hline MTRR $66 G A+M T R 2756 G A$ & 57 & 32 & 44 & 0.580 & $1.112(0.764-1.617)$ \\
\hline
\end{tabular}

${ }^{a}$ Adjusted for age and sex.

${ }^{\mathrm{b}}$ Mean survival time was provided when MST could not be calculated.

Although the MTHFR $1298 C A+C C$ genotypes were not associated with overall survival in univariate analysis, significant protective effect occurred when the above were combined with TS 5'-UTR $2 R 3 R+3 R 3 R$ genotypes $(\mathrm{HR}=0.536,95 \% \mathrm{CI}=0.315-0.913$, log-rank $p=0.022$, Table 4). Compared to $1298 A A+T S 5^{\prime}$-UTR $2 R 2 R$ genotypes, MST of patients with $1298 C A+C C$ and $T S 5^{\prime}$-UTR $2 R 3 R+3 R 3 R$ genotypes was extended from 30 months to 98 months (Table 4). The overall survival of GC patients was obviously extended and shown in Figure 3.

\section{DISCUSSION}

In this study, we investigated the effects of polymorphisms and their interactions in OCM pathway on survival of GC patients. The results demonstrated that the polymorphisms of MTRR $66 A>G$ and MTHFR $1298 A>C$ increased the survival of GC in a Chinese population. The MST of GC patients were strongly affected by MTHFR $1298 A>C$, TS 5'-UTR copy numbers and interactions between MTRR 66A $>G$ and MTR 2756A $>G$.

DNA dysmethylation is one of the crucial events for cancer development. It is well known that hypermethylation on promoters of tumor suppressor genes causes human cancers. MTRR and MTR maintained adequate levels of methionine, which functioned as a precursor for the universal methyl group donor S-adenosylmethionine [12]. The mutation of MTRR $66 \mathrm{~A}>G$ led to abnormal DNA methylation and altered nucleotide synthesis and repair [21]. MTRR $66 A>G$ polymorphism has been shown to increase risk of esophageal, colorectal and lung cancer $[11,12,14]$. However, some groups reported that the polymorphism had no significant effect on colorectal and breast cancers or cervical cancer [28, 29]. Our present result showed that MTRR $66 A>G$ polymorphism displayed a protective effect on GC among Chinese population (Table 2 and Figure 1), which was similar to the results in prostate cancer and colon cancer [30, 31]. Clinical analysis for functional contribution of polymorphism with multiple subgroups on the basis of clinical characteristics was vital to identify the potential prognostic markers in diverse stages of cancer progression. Several other studies have also demonstrated that the clinical characteristics of GC were related to the survival of GC patients $[32,33]$. Our findings indicated that patients with MTRR $66 G A+G G$ genotypes had better survival among subgroups that have more pronounced diffuse type, greater depth of invasion (T2/T3/T4), higher-level lymph node metastasis (N1/N2/ N3), advanced TNM stages (III/IV), and 5-FU treatment. The results indicated that MTRR $66 G$ allele improved the survival of GC patients. It has been proposed that MTR activity could not be maintained at a high level because residue Ile22 to Met22 switch of MTRR caused by the polymorphism reduced it activity [34]. Therefore, MTR could not effectively generate methionine for DNA methylation. We postulated that reduced methylation 


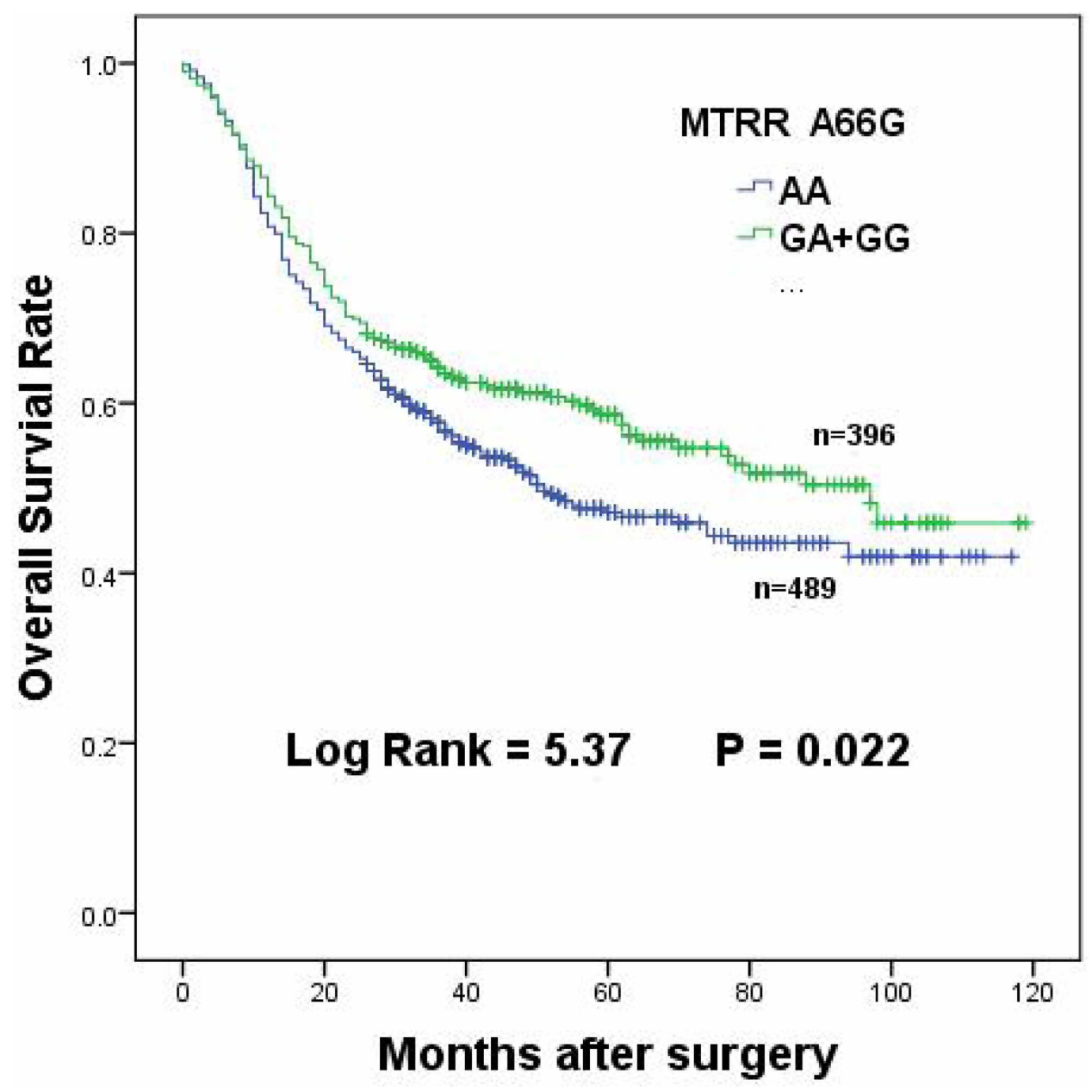

Figure 1: Overall survival of $M T R R 66 A>G$ dominant genotypes in gastric cancer patients.

on promoters of tumor suppressor genes would finally decrease activities of GC cells such as cell growth, invasiveness.

Our knowledge on the association of cancer risk and $M T R 2756 A>G$ polymorphism is very limited and inconsistent. Marcella et al. showed that MTR 2756GG genotype associated with decreased risk of colorectal cancer death [35]. A meta-analysis showed that MTR $2756 G G$ genotype obviously increased cancer risk in Asian populations, whereas a significantly reduced risk was observed in European populations [36]. Some other studies, consistent with our result among GC patients, demonstrated that no association was identified in colon cancer risk [37, 38]. In this study, we did not observe significant association of $G G$ genotype with survival time in GC patients (Table 2). Surprisingly, we found MTR $2756 G A+G G$ polymorphisms (Asp868 to Gly868 switch) neutralized the effects of MTRR $66 G A+G G$ on prolonged survival of GC patients (Table 4, Figure 2). Although there is no crystal structure data on MTRR-MTR interactions, based on our data, we could deduce that Ile22 of MTRR and Asp868 of $M T R$ are crucial for $M T R R-M T R$ interactions. Met22 switch of $M T R R$ may impair MTRR-MTR interaction, while three-dimensional conformation change caused by Gly868 switch of MTR may at least partially compensate and restore their interactions.

The polymorphisms of MTHFR $1298 A>C$ and $677 C>T$ were reported to reduce MTHFR enzymatic activity, leading to an increase in the amount of 5,10MTHF [19]. 5,10-MTHF, a substrate for both TS and MTHFR, interacted with TS and FU to form a tertiary complex, which might strengthen the function of 5-FU. 5-FU, the most common chemotherapy drug, was used to treat many cancers including GC. TS was a primary target for 5-FU. It was reported that polymorphism of both MTHFR $1298 A>C$ and $677 C>T$ manifestly protected the survival of colorectal cancer patients [39]. Recent studies have demonstrated that $677 T$ allele significantly increased the protective effect on colorectal cancer and hepatocellular cancer patients [35, 40, 41]. However, even as the polymorphisms cause a glutamine-to-alanine switch in protein sequence, we found that only MTHFR $1298 C C$ genotype showed a comparatively favorable outcome in this study, indication of the protection of GC patient survival in a recessive way. And although polymorphisms of TS have been proposed to influence 5-FU sensitivity, 


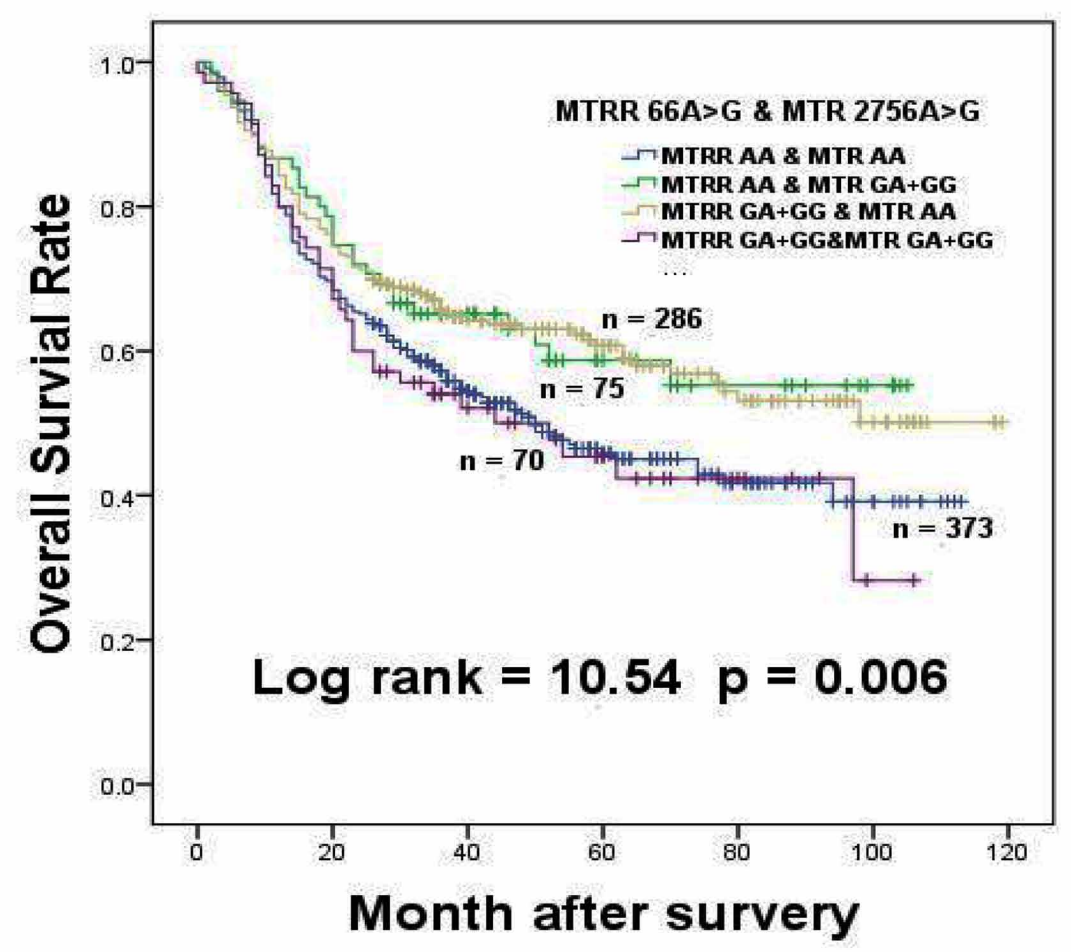

$\mathrm{B}$

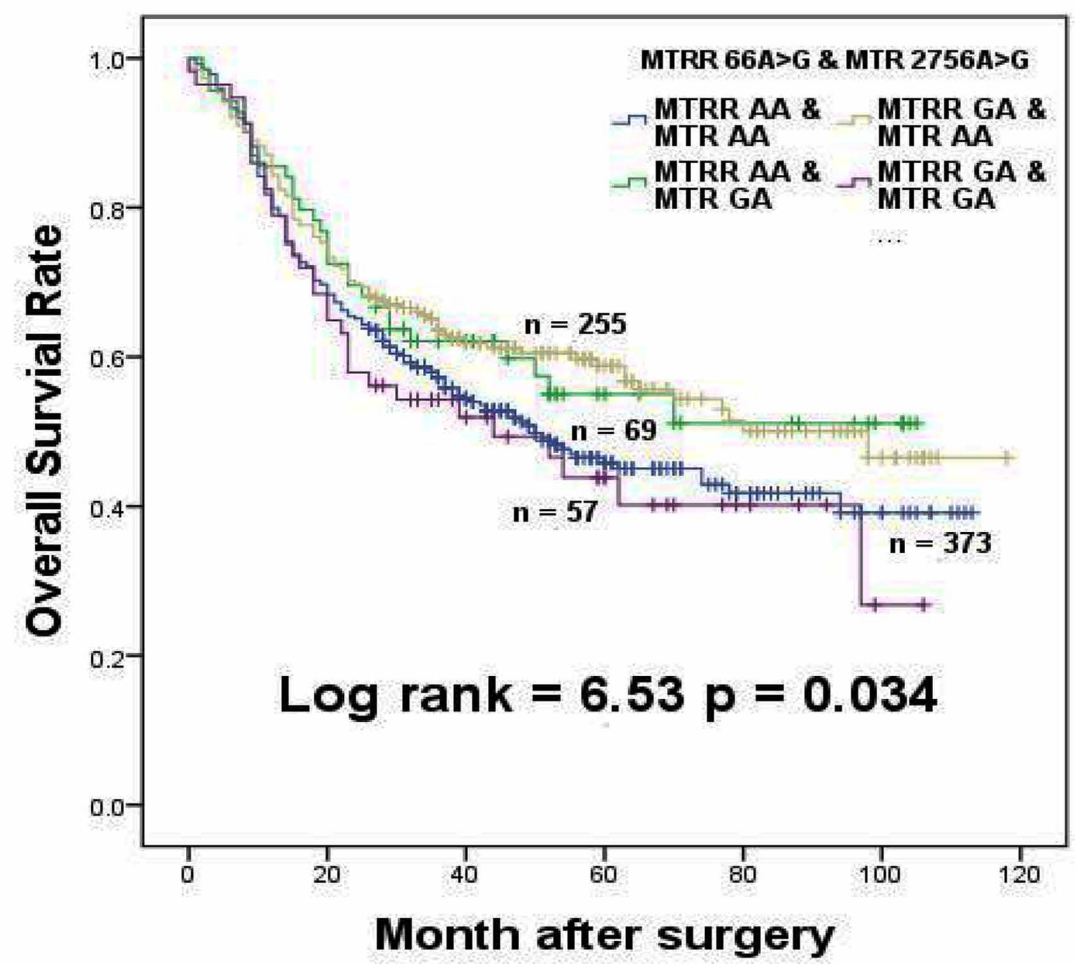

Figure 2: The effects of $M T R R 66 A>G$ interaction with $M T R 2756 A>G$ on survival of gastric cancer patients. (A) The effect of MTRR 66A $>\mathrm{G}$ interaction with MTR 2756A $>G$ in dominant model on the survival of gastric cancer patients. (B) The effect of MTRR $66 \mathrm{~A}>\mathrm{G}$ interaction with MTR 2756A $>\mathrm{G}$ in heterozygote model on the survival of gastric cancer patients. 


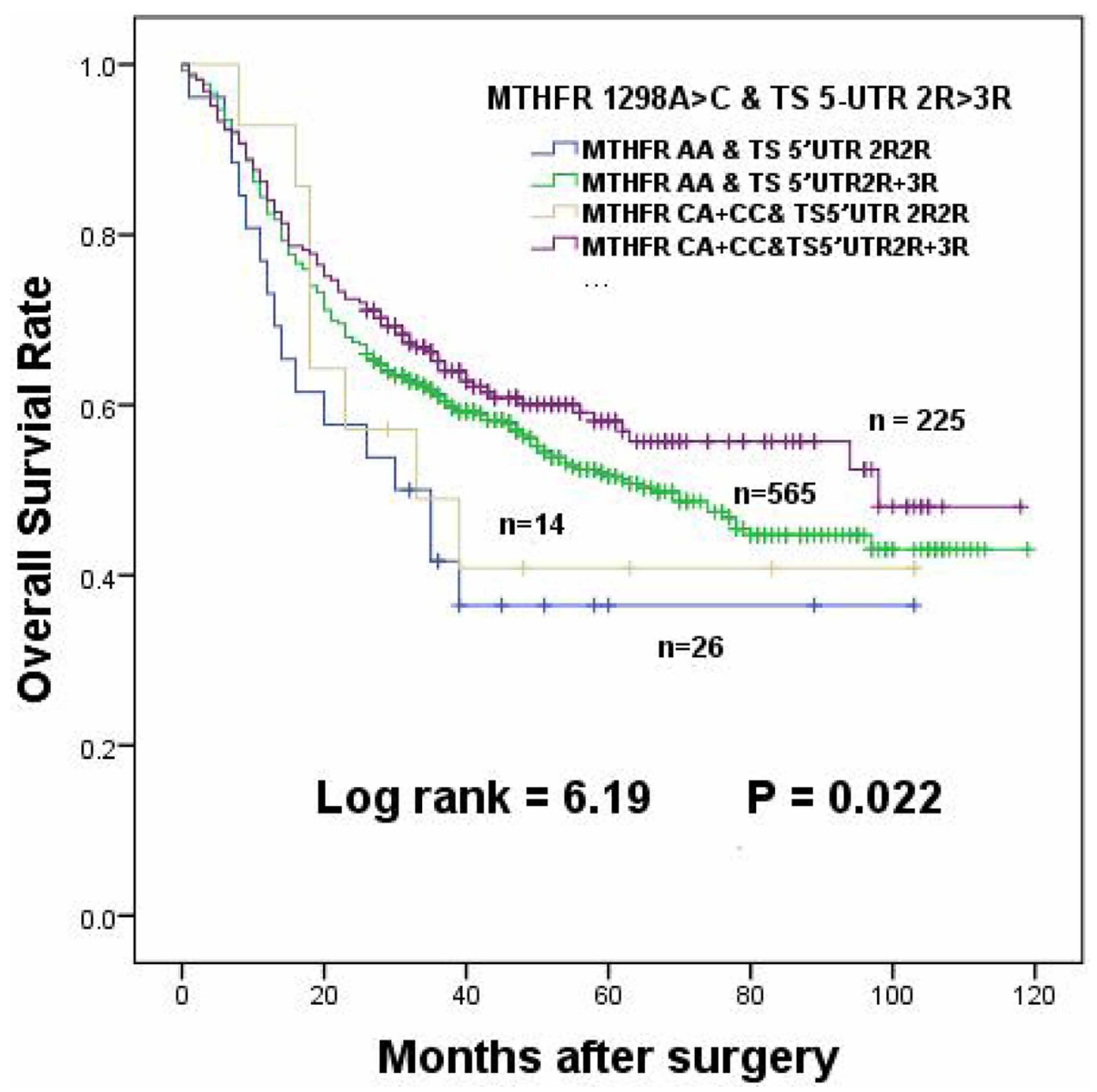

Figure 3. The effects of $M T H F R 1298 A>C$ interaction with $T S 5-U T R 2 R>3 R$ in dominant model on the survival of gastric cancer patients.

the accumulated data were controversial. One study showed that patients with $T S 5^{\prime}$-UTR $3 R 3 R$ genotype had poor prognosis in neoadjuvant treated advanced GC [42], while several other studies did not reveal any obviously prognostic differences among patients [4345]. In term of TS 3'-UTR polymorphisms, results from different groups were also not consistent. Some showed an increase of survival for colorectal cancer patients treated with 5-FU based adjuvant chemotherapy [46, 47], whereas others reported no obvious difference [43, 48]. In this study, no obvious relationship was found between the polymorphisms of TS 3'-UTR and 5-UTR genotypes with patient survival (Table 2). Interestingly, we observed $T S 5^{\prime} \mathrm{UTR} 2 R 3 R+3 R 3 R$ genotypes could interact with MTHFR $1298 C A+C C$ polymorphisms. They jointly reduced the risk of death of GC patients although each did not show detectable effect independently (Table 4). Patients carrying MTHFR 1298AA and TS 5-UTR $2 R 2 R$ genotypes showed a relatively poor prognosis as compared to those with MTHFR $1298 C A+C C$ and $T S$ 5 -UTR $2 R 3 R+3 R 3 R$ genotypes. Because $3 R$ exhibits better translational efficiency than $2 R$, more 5,10-MTHF,
TS and 5-FU complexes could be formed; it also displays better protective effect on GC progression to a certain extent [49].

In summary, our findings showed that MTHFR $1298 A>C$ and MTRR $66 A>G$ polymorphisms were related to the survival of GC patients, which indicated that these polymorphisms may be useful biomarkers for more accurate assessments of GC prognosis in the Chinese population. Further investigations on gene-gene interactions that may enhance or neutralize the effects of each individual polymorphism are needed.

\section{PATIENTS AND METHODS}

\section{Patient samples}

All 919 GC patients were recruited at the Yixing People's Hospital (Yixing, Jiangsu Province, China) between January 1999 and December 2006. They were histopathologically diagnosed and underwent surgery. No patient had received radiotherapy or chemotherapy before surgery. The patients' clinical characteristics were 
summarized in Table 1, with the maximum follow-up time of 119.0 months and the median follow-up time of 68.5 months. We classified the histopathology of GC into intestinal or diffuse types according to Lauren's Standard [50]. The TNM stages were evaluated according to the TNM classification of the American Joint Committee on Cancer (AJCC cancer staging manual, seventh edition). The retrospective cohort study was approved by the Institutional Review Board of Nanjing Medical University (Nanjing, China). All patients signed an informed consent on using clinical specimen for medical research in this study.

\section{Determination of polymorphism incidences}

Genomic DNA was extracted from paraffin sections postoperative tissues by proteinase $\mathrm{K}$ digestion, isopropanol extraction, and ethanol precipitation [32]. Polymorphisms were measured by SNaPshot technology with an ABI fluorescence-based assay allelic discrimination method (Applied Biosystems, Forster City, $\mathrm{CA}$ ) or automated sequencing as previously described [51]. Primers were custom made and their sequences were listed in Supplementary Table S4. An ABI3130 genetic analyzer was used to analyze the polymorphisms, and Genemapper4.0 software was used to determine genotypes (Applied Biosystems). Two people independently performed genotyping assays in a blind fashion. 10\% random samples were selected to validate genotypes, and the results were $100 \%$ concordant.

\section{Statistical analysis}

Mean survival time was used in this study if the median survival time (MST) could not be calculated. The overall survival time of each patient was calculated from the date of surgery until death or the last followup (March 31, 2009). The correlations of each genotype and combinations of genotypes with clinicopathologic parameters were compared. Student $t$-test and the Pearson were employed in this study based on the types of variables. Survival analyses were carried out by Kaplan-Meier plots and log-rank tests in SPSS version 20.0 (SPSS Inc, Chicago, IL, USA). We used univariate or multivariate Cox regression analysis to estimate $95 \%$ confidence intervals (CIs), and crude/adjusted hazard ratios (HRs). All of the tests were two-sided and $p<0.05$ was considered statistically significant.

\section{ACKNOWLEDGMENTS}

The work was partly supported by The National Basic Research Development Program (Grant No. 2013CB911300), Grants from National Natural Science Foundation of China (81272469), the clinical special project for Natural Science Foundation of Jiangsu
Province (Grant No. BL2012016), and the grant from Nanjing 12th Five-Year key Scientific Project of medicine to Dr. Jinfei Chen; Grants from National Natural Science Foundation of China (81471964) and the general research grant of Hong Kong (No. 14105214, 464512) to Dr. MingLiang HE.

\section{CONFLICTS OF INTEREST}

The authors have no conflicts of interest to declare.

\section{REFERENCES}

1. Jemal A, Bray F, Center MM, Ferlay J, Ward E, Forman D. Global cancer statistics. CA Cancer J Clin. 2011; 61:69-90.

2. Amedei A, Benagiano M, della Bella C, Niccolai E, D'Elios MM. Novel immunotherapeutic strategies of gastric cancer treatment. J Biomed Biotechnol. 2011; 2011:437348.

3. Becker KF, Keller G, Hoefler H. The use of molecular biology in diagnosis and prognosis of gastric cancer. Surg Oncol. 2000; 9:5-11.

4. Cheng J, Fan XM. Role of cyclooxygenase-2 in gastric cancer development and progression. World J Gastroenterol. 2013; 19:7361-8.

5. Wadhwa R, Song S, Lee JS, Yao Y, Wei Q, Ajani JA. Gastric cancer-molecular and clinical dimensions. Nat Rev Clin Oncol. 2013; 10:643-55.

6. Choi SW, Mason JB. Folate and carcinogenesis: an integrated scheme. J Nutr. 2000; 130:129-32.

7. Naushad SM, Pavani A, Digumarti RR, Gottumukkala SR, Kutala VK. Epistatic interactions between loci of onecarbon metabolism modulate susceptibility to breast cancer. Mol Biol Rep. 2011; 38:4893-901.

8. Chen J, Gammon MD, Chan W, Palomeque C, Wetmur JG, Kabat GC, Teitelbaum SL, Britton JA, Terry MB, Neugut AI, Santella RM. One-carbon metabolism, MTHFR polymorphisms, and risk of breast cancer. Cancer Res. 2005; 65:1606-14.

9. Lissowska J, Gaudet MM, Brinton LA, Chanock SJ, Peplonska B, Welch R, Zatonski W, SzeszeniaDabrowska N, Park S, Sherman M, Garcia-Closas M. Genetic polymorphisms in the one-carbon metabolism pathway and breast cancer risk: a population-based case-control study and meta-analyses. Int J Cancer. 2007; 120:2696-703.

10. Ulrich CM, Bigler J, Velicer CM, Greene EA, Farin FM, Potter JD. Searching expressed sequence tag databases: discovery and confirmation of a common polymorphism in the thymidylate synthase gene. Cancer Epidemiol Biomarkers Prev. 2000; 9:1381-5.

11. Stolzenberg-Solomon RZ, Qiao YL, Abnet CC, Ratnasinghe DL, Dawsey SM, Dong ZW, Taylor PR, Mark $\mathrm{SD}$. Esophageal and gastric cardia cancer risk and folate- and vitamin B(12)-related polymorphisms in Linxian. Cancer Epidemiol Biomarkers Prev. China: 2003; 12:1222-6. 
12. Pardini B, Kumar R, Naccarati A, Prasad RB, Forsti A, Polakova V, Vodickova L, Novotny J, Hemminki K, Vodicka P. MTHFR and MTRR genotype and haplotype analysis and colorectal cancer susceptibility in a case-control study from the Czech Republic. Mutat Res. 2011; 721:74-80.

13. Zhang Z, Shi Q, Liu Z, Sturgis EM, Spitz MR, Wei Q. Polymorphisms of methionine synthase and methionine synthase reductase and risk of squamous cell carcinoma of the head and neck: a case-control analysis. Cancer Epidemiol Biomarkers Prev. 2005; 14:1188-93.

14. Shi Q, Zhang Z, Li G, Pillow PC, Hernandez LM, Spitz MR, Wei Q. Polymorphisms of methionine synthase and methionine synthase reductase and risk of lung cancer: a case-control analysis. Pharmacogenet Genomics. 2005; 15:547-55.

15. Yoo JY, Kim SY, Hwang JA, Hong SH, Shin A, Choi IJ, Lee YS. Association study between folate pathway gene single nucleotide polymorphisms and gastric cancer in Koreans. Genomics Inform. 2012; 10:184-93.

16. Chang SC, Chang PY, Butler B, Goldstein BY, Mu L, Cai L, You NC, Baecker A, Yu SZ, Heber D, Lu QY, Li L, Greenland S, et al. Single nucleotide polymorphisms of one-carbon metabolism and cancers of the esophagus, stomach, and liver in a Chinese population. PLoS One. 2014; 9:e109235.

17. Han SS, Sue LY, Berndt SI, Selhub J, Burdette LA, Rosenberg PS, Ziegler RG. Associations between genes in the one-carbon metabolism pathway and advanced colorectal adenoma risk in individuals with low folate intake. Cancer Epidemiol Biomarkers Prev. 2012; 21:417-27.

18. Zhang L, Meng X, Ju X, Cai H, Li P, Cao Q, Shao P, Qin C, Yin C. One-carbon metabolism pathway gene variants and risk of clear cell renal cell carcinoma in a Chinese population. PLoS One. 2013; 8:e81129.

19. Frosst P, Blom HJ, Milos R, Goyette P, Sheppard CA, Matthews RG, Boers GJ, den Heijer M, Kluijtmans LA, van den Heuvel LP, et al. A candidate genetic risk factor for vascular disease: a common mutation in methylenetetrahydrofolate reductase. Nat Genet. 1995; 10:111-3.

20. Ott K, Rachakonda PS, Panzram B, Keller G, Lordick F, Becker K, Langer R, Buechler M, Hemminki K, Kumar R. DNA repair gene and MTHFR gene polymorphisms as prognostic markers in locally advanced adenocarcinoma of the esophagus or stomach treated with cisplatin and 5-fluorouracil-based neoadjuvant chemotherapy. Ann Surg Oncol. 2011; 18:2688-98.

21. Laraqui A, Allami A, Carrie A, Coiffard AS, Benkouka F, Benjouad A, Bendriss A, Kadiri N, Bennouar N, Benomar A, Guedira A, Raisonnier A, Fellati S, et al. Influence of methionine synthase (A2756G) and methionine synthase reductase (A66G) polymorphisms on plasma homocysteine levels and relation to risk of coronary artery disease. Acta Cardiol. 2006; 61:51-61.

22. Kawakami K, Salonga D, Park JM, Danenberg KD, Uetake H, Brabender J, Omura K, Watanabe G, Danenberg PV. Different lengths of a polymorphic repeat sequence in the thymidylate synthase gene affect translational efficiency but not its gene expression. Clin Cancer Res. 2001; 7:4096-101.

23. Horie N, Aiba H, Oguro K, Hojo H, Takeishi K. Functional analysis and DNA polymorphism of the tandemly repeated sequences in the 5 '-terminal regulatory region of the human gene for thymidylate synthase. Cell Struct Funct. 1995; 20:191-7.

24. Huang CL, Yokomise H, Kobayashi S, Fukushima M, Hitomi S, Wada H. Intratumoral expression of thymidylate synthase and dihydropyrimidine dehydrogenase in nonsmall cell lung cancer patients treated with 5-FU-based chemotherapy. Int J Oncol. 2000; 17:47-54.

25. Salonga $\mathrm{D}$, Danenberg $\mathrm{KD}$, Johnson $\mathrm{M}$, Metzger $\mathrm{R}$, Groshen S, Tsao-Wei DD, Lenz HJ, Leichman CG, Leichman L, Diasio RB, Danenberg PV. Colorectal tumors responding to 5-fluorouracil have low gene expression levels of dihydropyrimidine dehydrogenase, thymidylate synthase, and thymidine phosphorylase. Clin Cancer Res. 2000; 6:1322-7.

26. Mandola MV, Stoehlmacher J, Zhang W, Groshen S, $\mathrm{Yu}$ MC, Iqbal S, Lenz HJ, Ladner RD. A 6 bp polymorphism in the thymidylate synthase gene causes message instability and is associated with decreased intratumoral TS mRNA levels. Pharmacogenetics. 2004; 14:319-27.

27. Akisik E, Dalay N. Functional polymorphism of thymidylate synthase, but not of the COMT and IL-1B genes, is associated with breast cancer. J Clin Lab Anal. 2007; 21:97-102.

28. Burcos T, Toma M, Stavarachi M, Cimponeriu D, Apostol P, Popa E, Stanilescu S, Popa I, Radu I, Serafinceanu C, Panduru N, Belusica L, Gavrila L. MTRR polymorphism and the risk for colorectal and breast cancer in Romanian patients-a preliminary study. Chirurgia (Bucur). 2010; 105:379-82.

29. Mostowska A, Myka M, Lianeri M, Roszak A, Jagodzinski PP. Folate and choline metabolism gene variants and development of uterine cervical carcinoma. Clin Biochem. 2011; 44:596-600.

30. Collin SM, Metcalfe C, Refsum H, Lewis SJ, Smith GD, Cox A, Davis M, Marsden G, Johnston C, Lane JA, Donovan JL, Neal DE, Hamdy FC, et al. Associations of folate, vitamin B12, homocysteine, and folate-pathway polymorphisms with prostate-specific antigen velocity in men with localized prostate cancer. Cancer Epidemiol Biomarkers Prev. 2010; 19:2833-8.

31. Jokic M, Brcic-Kostic K, Stefulj J, Catela Ivkovic T, Bozo L, Gamulin M, Kapitanovic S. Association of MTHFR, MTR, MTRR, RFC1, and DHFR gene polymorphisms with susceptibility to sporadic colon cancer. DNA Cell Biol. 2011; 30:771-6.

32. Wang M, Bai J, Tan Y, Wang S, Tian Y, Gong W, Zhou Y, Gao Y, Zhou J, Zhang Z. Genetic variant in PSCA predicts survival of diffuse-type gastric cancer in a Chinese population. Int J Cancer. 2011; 129:1207-13. 
33. Luo D, Gao Y, Wang S, Wang M, Wu D, Wang W, Xu M, Zhou J, Gong W, Tan Y, Zhang Z. Genetic variation in PLCE1 is associated with gastric cancer survival in a Chinese population. J Gastroenterol. 2011; 46:1260-6.

34. Olteanu H, Munson T, Banerjee R. Differences in the efficiency of reductive activation of methionine synthase and exogenous electron acceptors between the common polymorphic variants of human methionine synthase reductase. Biochemistry. 2002; 41:13378-85.

35. Martinelli M, Scapoli L, Mattei G, Ugolini G, Montroni I, Zattoni D, Rosati G, Solmi R. A candidate gene study of one-carbon metabolism pathway genes and colorectal cancer risk. Br J Nutr. 2013; 109:984-9.

36. Yu K, Zhang J, Zhang J, Dou C, Gu S, Xie Y, Mao Y, Ji C. Methionine synthase A2756G polymorphism and cancer risk: a meta-analysis. Eur J Hum Genet. 2010; 18:370-8.

37. Ulrich CM, Curtin K, Potter JD, Bigler J, Caan B, Slattery ML. Polymorphisms in the reduced folate carrier, thymidylate synthase, or methionine synthase and risk of colon cancer. Cancer Epidemiol Biomarkers Prev. 2005; 14:2509-16.

38. Eussen SJ, Vollset SE, Igland J, Meyer K, Fredriksen A, Ueland PM, Jenab M, Slimani N, Boffetta P, Overvad K, Tjonneland A, Olsen A, Clavel-Chapelon F, et al. Plasma folate, related genetic variants, and colorectal cancer risk in EPIC. Cancer Epidemiol Biomarkers Prev. 2010; 19:1328-40.

39. Rai PS, Pai GC, Alvares JF, Bellampalli R, Gopinath PM, Satyamoorthy K. Intraindividual somatic variations in MTHFR gene polymorphisms in relation to colon cancer. Pharmacogenomics. 2014; 15:349-59.

40. Huang Y, Han S, Li Y, Mao Y, Xie Y. Different roles of MTHFR C677T and A1298C polymorphisms in colorectal adenoma and colorectal cancer: a meta-analysis. J Hum Genet. 2007; 52:73-85.

41. Zhang H, Liu C, Han YC, Ma Z, Zhang H, Ma Y, Liu X. Genetic variations in the one-carbon metabolism pathway genes and susceptibility to hepatocellular carcinoma risk: a case-control study. Tumour Biol. 2014.

42. Ott K, Vogelsang H, Marton N, Becker K, Lordick F, Kobl M, Schuhmacher C, Novotny A, Mueller J, Fink U, Ulm K, Siewert JR, Hofler H, et al. The thymidylate synthase tandem repeat promoter polymorphism: a predictor for tumor-related survival in neoadjuvant treated locally advanced gastric cancer. Int J Cancer. 2006; 119:2885-94.

43. Lecomte T, Ferraz JM, Zinzindohoue F, Loriot MA, Tregouet DA, Landi B, Berger A, Cugnenc PH, Jian R,
Beaune P, Laurent-Puig P. Thymidylate synthase gene polymorphism predicts toxicity in colorectal cancer patients receiving 5-fluorouracil-based chemotherapy. Clin Cancer Res. 2004; 10:5880-8.

44. Goekkurt E, Hoehn S, Wolschke C, Wittmer C, Stueber C, Hossfeld DK, Stoehlmacher J. Polymorphisms of glutathione S-transferases (GST) and thymidylate synthase (TS)novel predictors for response and survival in gastric cancer patients. Br J Cancer. 2006; 94:281-6.

45. Hua D, Huang ZH, Mao Y, Deng JZ. Thymidylate synthase and thymidine phosphorylase gene expression as predictive parameters for the efficacy of 5-fluorouracil-based adjuvant chemotherapy for gastric cancer. World J Gastroenterol. 2007; 13:5030-4.

46. Dotor E, Cuatrecases M, Martinez-Iniesta M, Navarro M, Vilardell F, Guino E, Pareja L, Figueras A, Mollevi DG, Serrano T, de Oca J, Peinado MA, Moreno V, et al. Tumor thymidylate synthase 1494del6 genotype as a prognostic factor in colorectal cancer patients receiving fluorouracilbased adjuvant treatment. J Clin Oncol. 2006; 24:1603-11.

47. Stoehlmacher J, Park DJ, Zhang W, Yang D, Groshen S, Zahedy S, Lenz HJ. A multivariate analysis of genomic polymorphisms: prediction of clinical outcome to 5-FU/ oxaliplatin combination chemotherapy in refractory colorectal cancer. Br J Cancer. 2004; 91:344-54.

48. Pare L, Altes A, Ramon y Cajal T, Del Rio E, Alonso C, Sedano L, Barnadas A, Baiget M. Influence of thymidylate synthase and methylenetetrahydrofolate reductase gene polymorphisms on the disease-free survival of breast cancer patients receiving adjuvant 5-fluorouracil/methotrexatebased therapy. Anticancer Drugs. 2007; 18:821-5.

49. Mandola MV, Stoehlmacher J, Muller-Weeks S, Cesarone G, Yu MC, Lenz HJ, Ladner RD. A novel single nucleotide polymorphism within the $5^{\prime}$ tandem repeat polymorphism of the thymidylate synthase gene abolishes USF-1 binding and alters transcriptional activity. Cancer Res. 2003; 63:2898-904.

50. Lauren P. The two histological main types of gastric carcinoma: diffuse and so-called intestinal-type carcinoma. An attempt at a histo-clinical classification. Acta Pathol Microbiol Scand. 1965; 64:31-49.

51. Xiao HW, Lai XY, Luo Y, Shi JM, Tan YM, He JS, Xie WZ, Li L, Zhu XL, Zhu JJ, Sun J, Wei GQ, Jin L, et al. Relationship between TNFA, TNFB, and TNFRII gene polymorphisms and outcome after unrelated hematopoietic cell transplantation in a Chinese population. Bone Marrow Transplant. 2011; 46:400-7. 